\title{
Process performance and microbial community structure in thermophilic trickling biofilter reactors for biogas upgrading
}

Porté, Hugo; Kougias, Panagiotis ; Alfaro, Natalia; Treu, Laura; Campanaro, Stefano; Angelidaki, Irini

Published in:

Science of the Total Environment

Link to article, DOI:

10.1016/j.scitotenv.2018.11.289

Publication date:

2019

Document Version

Peer reviewed version

Link back to DTU Orbit

Citation (APA):

Porté, H., Kougias, P., Alfaro, N., Treu, L., Campanaro, S., \& Angelidaki, I. (2019). Process performance and microbial community structure in thermophilic trickling biofilter reactors for biogas upgrading. Science of the Total Environment, 655, 529-538. https://doi.org/10.1016/j.scitotenv.2018.11.289

\section{General rights}

Copyright and moral rights for the publications made accessible in the public portal are retained by the authors and/or other copyright owners and it is a condition of accessing publications that users recognise and abide by the legal requirements associated with these rights.

- Users may download and print one copy of any publication from the public portal for the purpose of private study or research.

- You may not further distribute the material or use it for any profit-making activity or commercial gain

- You may freely distribute the URL identifying the publication in the public portal 


\title{
structure in thermophilic trickling biofilter reactors for
}

\section{biogas upgrading}

\author{
Hugo Porté ${ }^{a+}$, Panagiotis G. Kougias ${ }^{\mathrm{a}^{*+}}$, Natalia Alfaro ${ }^{\mathrm{a}, \mathrm{b}}$, Laura Treu ${ }^{\mathrm{a}}$, \\ Stefano Campanaro ${ }^{\mathrm{c}}$, Irini Angelidaki ${ }^{\mathrm{a}}$
}

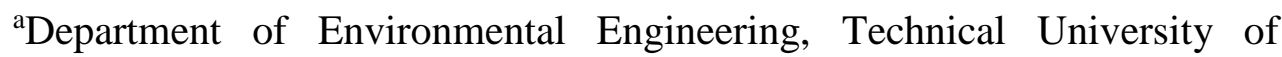
Denmark, Kgs. Lyngby, DK-2800, Denmark

${ }^{\mathrm{b}}$ Institute of Sustainable Processes, Department of Chemical Engineering and Environmental Technology, Escuela de Ingenierías Industriales, Sede Dr. Mergelina, University of Valladolid, Dr. Mergelina s/n, 47011 Valladolid, Spain.

cDepartment of Biology, University of Padua, 35131 Padua, Italy

*Corresponding author and address: Panagiotis G. Kougias, Department of Environmental Engineering, Technical University of Denmark, Bld 113, 2800 Lyngby Denmark, E-mail address: panak@env.dtu.dk, Tel.: +45 45251454

${ }^{+}$These authors contributed equally to the work 


\section{Highlights}

- Biological biogas upgrading process was evaluated in trickling biofilter reactors

- Gas input was directed in concurrent or countercurrent flow of the trickling media

- Stable and robust operation was achieved by means of a single-pass gas flow

- Methane concentration in output gas was higher than $97 \%$

- Hydrogenotrophic methanogens were localised in biofilm 


\section{Abstract}

This study evaluated the process performance and determined the microbial community structure of two lab-scale thermophilic trickling biofilter reactors used for biological methanation of hydrogen and carbon-dioxide for a total period of 94 days. Stable and robust operation was achieved by means of a single-pass gas flow. The quality of the output gas (>97\%) was comparable to the methane purity achieved by commercial biogas upgrading systems fulfilling the specifications to be used as substitute to natural gas. The reactors' methane productivity reached more than 1.7 $\mathrm{L}_{\mathrm{CH}} /\left(\mathrm{L}_{\mathrm{R} . \mathrm{d}}\right)$ at hydrogen loading rate of 7.2 $\mathrm{LH}_{\mathrm{H}} /\left(\mathrm{L}_{\mathrm{R}} . \mathrm{d}\right)$. The spatial distribution of the microbial consortia localized in the liquid media and biofilm enabled us to gain a deeper understanding on how the microbiome is structured inside the trickling biofilter. Sequencing results revealed a significant predominance of Methanothermobacter sp. in the biofilm. Unknown members of the class Clostridia were highly abundant in biofilm and liquid media, while acetate utilising bacteria predominated in liquid samples.

\section{Keywords}

Biomethanation; biogas upgrading; trickling biofilter; Power-to-Gas

\section{Introduction}

Biogas typically consists of methane $\left(\mathrm{CH}_{4}\right)(50-70 \%)$, carbon-dioxide $\left(\mathrm{CO}_{2}\right)(30-$ $50 \%$ ), and other impurities, such as hydrogen sulphide, ammonia, moisture etc, in significantly lower concentrations (Kougias and Angelidaki, 2018). Even though these impurities, such as hydrogen sulphide, are extremely corrosive for the equipment and needs to be removed, it is apparent, the $\mathrm{CO}_{2}$ fraction of biogas reduces its calorific 
value. For that reason, a specific process, the so called "biogas upgrading", is applied in order to remove or transform the contained $\mathrm{CO}_{2}$, and thereby, increase the methane concentration of the final output gas (Angelidaki et al., 2018). Biogas purification increases the energy density of the gas and broaden the options for further applications; besides combined heat and power generation, its injection into natural gas infrastructures, efficient transport after gas compression, large-scale storage, and use as vehicle fuel are possible (Sun et al., 2015).

An attractive method for increasing the $\mathrm{CH}_{4}$ content of biogas is based on biological methanation of $\mathrm{H}_{2}$ and $\mathrm{CO}_{2}$. To maintain a sustainable energy process, the $\mathrm{H}_{2}$ must be produced by sustainable sources, such as water electrolysis powered by off-peak electricity surplus from intermittent renewable energies (e.g. solar and wind power). Nowadays, commercial water electrolysers are able to cold start within a few minutes (Bhandari et al., 2014; Persson et al., 2015), enabling the system to offer grid-balancing services, assisting the power grid to meet the supply of electricity to the demand (Guinot et al., 2015). Therefore, this Power-to-Gas technology provides large-scale energy storage, as the end-use of biomethane is not limited in the gas grid and also avoids safety management issues associated with $\mathrm{H}_{2}$ production and handling (Collet et al., 2017). Currently, there are three concepts for biological biogas upgrading, namely "in-situ", "ex-situ" and "hybrid" (Kougias et al., 2017). During the "in-situ" process, $\mathrm{H}_{2}$ is directly injected into a conventional biogas reactor, and thus the endogenous $\mathrm{CO}_{2}$ is hydrogenated to $\mathrm{CH}_{4}$. The advantages of such technology rely to its simplicity and reduced costs for implementation as it mainly utilises the existing infrastructure of the biogas plants. However, these systems are prone to increase the $\mathrm{pH}$ and hinder the degradation of Volatile Fatty Acids, which affects negatively the kinetics of the 
anaerobic digestion process (Angelidaki et al., 2018). Therefore, the development of "ex-situ" biomethanation systems is gaining increased interest as this concept aims to optimise the upgrading process in dedicated external reactors.

Till now, several studies investigated the ex-situ biogas upgrading process in different temperature conditions (Bassani et al., 2017; Rachbauer et al., 2016; Strübing et al., 2017). It was found that the reactors' performance and efficiency of the system is improved at thermophilic conditions (Yun et al., 2017). However, $\mathrm{H}_{2}$ is much less soluble in water (e.g. at thermophilic temperature about 500 times less soluble than $\mathrm{CO}_{2}$ ) (Ahern et al., 2015). Therefore, the limiting factor in both in-situ and ex-situ systems is the efficient diffusion of $\mathrm{H}_{2}$ into the liquid phase, which will make it available for the microorganisms (Alfaro et al., 2018; Bassani et al., 2016; Díaz et al., 2015; Martin et al., 2013). To address this technical challenge, different reactor configurations, at lab or pilot scale, aiming at maximising the $\mathrm{H}_{2}$ gas-liquid transfer have been investigated (Alfaro et al., 2018; Bassani et al., 2016; Díaz et al., 2015; Ju et al., 2008; Martin et al., 2013; Wang et al., 2013).

More recently, the exploitation of trickling biofilter (TBF) reactors has been proposed to support efficient biomethanation (Alitalo et al., 2015; Burkhardt et al., 2015; Rachbauer et al., 2016; Strübing et al., 2017). TBF reactors consist of a column that is packed with material of high specific surface area, on which biofilm is developed. The gases are forced through the packed bed either downwards or upwards and the liquid media is trickled and recycled over the packing material to provide moisture and nutrients, forming a thin liquid layer over the biofilm. Therefore, the TBF is composed of a three-phase system: a gas phase nearly filling the entire reactor, a liquid-phase trickling over the biofilm, and the biofilm itself attached to the packed-bed 
surfaces. The biofilm is composed of a specific arrangement of immobilised cells within a matrix of extracellular polymeric substances. This organisation results in symbiotic behaviours that optimize microbial relations (Garrett et al., 2008). Additionally, compared to systems where the microorganisms are suspended in liquid media, biofilms present certain advantages, such as immobilisation of the microbial community (avoiding discharge from the system) and increased resistance to inhibitory or toxic compounds (Hori and Matsumoto, 2010). Regarding previous experiments with TBF reactors at thermophilic conditions, two bioreactors in serial configuration (Alitalo et al., 2015) or one trickle bed system (Strübing et al., 2017) have been investigated with $\mathrm{H}_{2}$ and $\mathrm{CO}_{2}$ as gas substrates. In these studies, the gas mixture was injected in the reactor either in concurrent (Alitalo et al., 2015) or countercurrent flow (Strübing et al., 2017) to the liquid media but the possible influence of the injection direction on the biogas upgrading process is still unexplored. More specifically, to the best of our knowledge only one work has investigated a trickle bed system fed in concurrent mode (Dupnock and Deshusses, 2017). Moreover, the microbial community involved in exsitu biogas upgrading process in TBF reactors and their importance for successful operation of the system at thermophilic conditions remains uncharacterized. It is well known that the efficiency of the biomethanation process is strongly dependent on a balanced microbial consortium which is specialized in $\mathrm{H}_{2}$ utilization (Treu et al., 2018a). A high- resolution characterization of the microbial community in biogas upgrading systems will provide essential information for process optimization.

The present study aimed at evaluating the process performance and determining the microbial ecology of thermophilic TBF reactors performing biological methanation of $\mathrm{H}_{2}$ and $\mathrm{CO}_{2}$. Progressively reduced gas retention times were applied by increasing the 
influent gas mixture (i.e. simulating a biogas stream and the corresponding amount of $\mathrm{H}_{2}$ needed to react with the $\mathrm{CO}_{2}$ ) to assess the productivity and stability of the process. In addition, the gas mixture was injected in the reactors either in concurrent or countercurrent flow to the liquid media to identify potential differences in biomethanation efficiency. Furthermore, samples collected from the liquid phase and from the biofilm undergo high throughput $16 \mathrm{~S}$ rRNA amplicon sequencing to gain a deeper understanding on how is the microbial community structured inside the trickling filter. Linking the microbial ecology information with the outcomes from the reactor monitoring can provide essential information for designing robust anaerobic systems for biological biogas upgrade.

\section{Materials and methods}

\subsection{Inoculum}

Enriched hydrogenotrophic culture obtained from laboratory biogas upgrading column reactors (Bassani et al., 2017) was used for the initial inoculation of the TBF reactors. The inoculum had a $\mathrm{pH}$ of 8.03 , the concentration of total solids was $1.6 \pm 0.0$ $\%$ and the concentration of volatile solids was $0.6 \pm 0.0 \%$. The total Kjeldahl nitrogen was measured to be $2.03 \pm 0.11 \mathrm{~g} / \mathrm{L}$, the ammonia nitrogen equal to $1.63 \pm 0.06 \mathrm{~g} / \mathrm{L}$ and the concentration of volatile fatty acids was $304.8 \pm 5.7 \mathrm{mg} / \mathrm{L}$. During the start-up period, the reactors were inundated for 24 hours with inoculum to enhance the initial microbial adhesion, and thus, biofilm formation (Langer et al., 2014). Digestate collected from Snertinge biogas plant, Denmark, was used as nutrient source during the whole experimental work. More specifically, twice per week that liquid samples $(20 \mathrm{~mL})$ were obtained from the reactors for biochemical analyses, an isovolume of digestate 
was added in the liquid tank. The digestate was incubated at thermophilic conditions for a period of more than three months to ensure total degradation of the organic matter that would result in additional biogas generation inside the reactors influencing the mass balance.

\subsection{Reactors' setup and operation}

Two TBF reactors, operating at thermophilic temperature $\left(54 \pm 1^{\circ} \mathrm{C}\right)$ and atmospheric pressure, were used for the experiments. The difference between the two reactor configurations was the direction of the injected gas flow and the outlet gas port. The gas mixture in the first reactor, denoted as R1, was injected in a countercurrent flow to the trickling media, while the outlet gas port (i.e. port that allow gasses to exit the reactor) was placed at the top of the reactor (Fig. 1a). On the contrary, the influent gas in the second reactor, denoted as R2, was directed concurrently of the recirculating liquid. Therefore, an outlet port was placed in the bottom of the reactor so as the liquid, which would be saturated with gas, to be removed from the reactor and subsequently be recirculated (Fig. 1b). As previously mentioned, the reasoning for the differently applied gas injection was to investigate potential effect of the gas components densities and flow direction over the reactors' performance. Both reactors were made of poly(methyl methacrylate) and had $1 \mathrm{~L}$ working volume (packed bed) with dimension ratio length:diameter of 9:1. Glass rings (Sigma-Aldrich) were used as packing material (5x6 mm each with specific surface area of $\left.0.002 \mathrm{~m}^{2} / \mathrm{g}\right)$. A water recirculation system was used to heat the reactors by means of D10 mm silicon tubes wrapping their entire cylindrical surface. Polyethylene foam was used to cover the wrapped reactors for insulation. Each reactor configuration was connected with a glass vessel $(1$ L working 
volume), which contained the recirculation liquid media. The vessel was equipped with a thermal jacket so as to operate at stable thermophilic temperature $\left(54 \pm 1^{\circ} \mathrm{C}\right)$. The liquid was pumped out from the vessel and trickled over the packed bed through seven ports (each port had a diameter of $2 \mathrm{~mm}$ ) that were distributed at the upper lid of the reactors. The liquid recirculation took place for 30 seconds every half an hour using a peristaltic pump set at a flow rate of $2.8 \mathrm{~L} /\left(\mathrm{L}_{R} . \mathrm{d}\right)$. The feeding gas mixture was synthetically composed of $23 \% \mathrm{CH}_{4}, 15 \% \mathrm{CO}_{2}$ and $62 \% \mathrm{H}_{2}$, replicating a mixture of biogas (about $60 \% \mathrm{CH}_{4}$ and $40 \% \mathrm{CO}_{2}$ ) and $\mathrm{H}_{2}$ in stoichiometric proportions according to reaction (1).

$$
4 \mathrm{H}_{2}+\mathrm{CO}_{2} \rightarrow \mathrm{CH}_{4}+2 \mathrm{H}_{2} \mathrm{O} \quad\left(\Delta \mathrm{G}^{\circ}=-131 \mathrm{~kJ} / \mathrm{mol}\right)
$$

The gas feed was continuously introduced to the reactors using peristaltic pumps. No gas recirculation was applied, resulting in a single-pass plug flow operation. The experiment using both reactors lasted for a total of 94 days and was divided in four experimental periods, during which the gas retention time (GRT) of the reactors was reduced by increasing the gas feeding rate of the reactors. Thus, the periods were denoted as Period I (GRT=14h), Period II (GRT=7h), Period III (GRT=4.2h), and Period IV (GRT=2.1h). Experimental operation was progressed from one period to the next one when steady state conditions were achieved (i.e. less than 5\% variations of the output-gas composition).

\subsection{Analytical methods}

According to the Standard Methods for Examination of Water and Wastewater (APHA, 2005), total solids (Method 2540B) and volatile solids (Method 2540G) concentrations of the inoculum used was determined. The $\mathrm{pH}$ was measured using a 
digital PHM210 pH meter connected to the Gel pH electrode (pHC3105-8; Radiometer analytical). Output gas flows were measured daily by means of water displacement gasmetering systems (each cycle was $100 \mathrm{~mL}$ ). The composition of the influent and effluent gasses was measured three times per week using gas chromatographs (Mikrolab, Aarhus A/S, Denmark), equipped with a thermal conductivity detector (TCD). The injection port, detector and oven temperature was set at $50{ }^{\circ} \mathrm{C}$, while depending on the measurement, hydrogen or nitrogen was used as carrier gas. The determination of the volatile fatty acids (VFA) was performed twice a week using a gas chromatograph (Shimadzu GC-2010, Kyoto, Japan) equipped with a FID and an FFAP fused-silica capillary column, as previously described (Kougias et al., 2015). All measurements were performed in triplicate samples.

\subsection{Calculations}

The utilisation efficiency of $\mathrm{H}_{2}$, denoted as $\eta_{H_{2}}(\%)$ was determined according to the following equation:

$$
\eta_{H_{2}}=\frac{H_{2 u s e d}}{Q_{H_{2}, I N}} \cdot 100
$$

where $H_{2}$ used is the $\mathrm{H}_{2}$ utilisation rate expressed as $\mathrm{L}_{\mathrm{H} 2} / \mathrm{L}_{\mathrm{R}} \cdot \mathrm{d}$ and $Q_{\mathrm{H}_{2}, I N}$ is the $\mathrm{H}_{2}$ loading rate expressed as $\mathrm{L}_{\mathrm{H}} / \mathrm{L}_{\mathrm{R}} \cdot \mathrm{d}$. Similarly the $\mathrm{CO}_{2}$ utilisation efficiency $\left(\eta_{\mathrm{CO}_{2}}, \%\right)$ was calculated.

The methane production rate $\left(P_{\mathrm{CH}_{4}}, \mathrm{~L}_{\mathrm{CH}} / \mathrm{L}_{\mathrm{R}} \cdot \mathrm{d}\right)$ was determined by subtracting the methane volume that was contained in the influent gas mixture from the output gas as follows:

$P_{C_{4}}=Q_{C H_{4}, O U T}-Q_{C H_{4}, I N}$

where $Q_{C_{4}, \text { OUT }}$ is the outflow $\mathrm{CH}_{4}$ rate expressed as $\mathrm{L}_{\mathrm{CH} 4} / \mathrm{L}_{\mathrm{R}} \cdot \mathrm{d}$ and $Q_{C H_{4}, I N}$ is the $\mathrm{CH}_{4}$ 
that was injected in the reactors due to the gas mixture, expressed as $\mathrm{L}_{\mathrm{CH}} / \mathrm{L}_{\mathrm{R}} \cdot \mathrm{d}$.

\subsection{Microbial analysis}

At the end of the experiment (day 94) triplicate samples from the liquid media and from the biofilm that was created on the surface of the packing material located in the middle part of R2 were collected. Genomic DNA was extracted using the PowerSoil@ DNA Isolation Kit (MO BIO laboratories Inc., Carlsbad, CA USA) and following the instructions of the manufacturer. The quantity and quality assessment of the extracted DNA were performed using NanoDrop (ThermoFisher Scientific, Waltham, MA) and Qubit Fluorometer (ThermoFisher Scientific, Waltham, MA), respectively. Library preparation was performed on the V4 region of $16 \mathrm{~S}$ rRNA gene using universal primers (i.e. 515f/806r). Sequencing was performed using Illumina MiSeq platform. The raw sequenced data were processed using CLC Workbench software (V.8.0.2) with Microbial genomics module plug in (QIAGEN Bioinformatics, Germany). The detailed procedure followed was previously described by Treu et al. (2018b). BLASTn against $16 \mathrm{~S}$ ribosomal RNA (bacteria and archaea) database was used to assist and/or verify the taxonomical assignment obtained by CLC (Greengenes v13_5 database). Heat maps showing relative abundance and fold change of most relevant operational taxonomic units (OTUs) were done using Multiexperiment Viewer software (MeV 4.9.0) (Saeed et al., 2003). Statistical analysis and corresponding graphs were performed using STAMP software (Parks and Beiko, 2010) to assess the dissimilarity among the samples from the liquid media and from the biofilm identifying the significance of changes in relative abundance. The current study will focus on the high abundant OTUs (i.e. relative abundance higher than $0.5 \%$ with respect to the total number of sequences) which were 
present in at least one sample. Raw reads were deposited in Sequence Read Archive (SRA) database of NCBI under the BioProject PRJNA481013. Table 2 reports the sequencing results summary and the SRA IDs of each sample.

\section{Results and Discussion}

\subsection{Process performance of trickling biofilter reactors}

The TBF reactors achieved an output gas that was fulfilling the standards for substituting natural gas or could be used as transportation fuel in different countries.

The inoculation procedure with enriched hydrogenotrophic media was beneficial for the start-up process in the TBF reactors as it minimised the duration needed for the microbial adaptation. Indeed, the $\mathrm{CH}_{4}$ content in the output gas after three days of initial operation reached $93 \%$. In general, it was demonstrated that the biomethanation efficiency of both reactors was similar (Table 1, Fig. 2). More specifically, the $\mathrm{CH}_{4}$ concentration of the upgraded biogas was progressively increasing to up to 4.2 hours gas retention time (Period III) having a maximum $\mathrm{CH}_{4}$ content of approximately $99 \%$. On average, the $\mathrm{CH}_{4}$ production rate of the TBF reactors was 0.25 (Period I), 0.5 (Period II) and $0.88 \mathrm{LCH}_{4} /\left(\mathrm{L}_{\mathrm{R}} \cdot \mathrm{d}\right)$. A further reduction of the gas retention time to almost 2 hours led to an increment of the methane productivity to approximately 1.73 $\mathrm{L}_{\mathrm{CH} 4} /\left(\mathrm{L}_{\mathrm{R}} \cdot \mathrm{d}\right)$; nevertheless, the quality of the output gas was lowered (i.e. on average 95\% $\mathrm{CH}_{4}$ concentration). The decreased methane purity was attributed to the fact that the supplied $\mathrm{H}_{2}$ and $\mathrm{CO}_{2}$ was utilised for acetate production (homoacetogenesis) instead of methanogenesis. Similar findings were recently documented in another study performed which reported that acetate accumulation decreased the conversion efficiency of $\mathrm{CO}_{2}$ to $\mathrm{CH}_{4}$ in trickle bed reactors (Rachbauer et al., 2017). Indeed, the results from 
the VFA determination showed that there was a strong accumulation of short chain fatty acids; especially the acetate concentration in $\mathrm{R} 2$ increased from $113 \mathrm{mg} / \mathrm{L}$ in Period I to $643 \mathrm{mg} / \mathrm{L}$ in Period IV. It is known that VFA-degradation requires low hydrogen partial pressure (Fukuzaki et al., 1990). Therefore, the observed VFAs accumulation suggests that the $\mathrm{H}_{2}: \mathrm{CO}_{2}$ ratio fed to the reactor (4.13:1) was slightly too high, resulting in an excess of $\mathrm{H}_{2}$ that increased the $\mathrm{H}_{2}$ partial pressure and hindered the degradation of VFA. To verify the hypothesis, the gas mixture of R2 during Period IV was temporarily changed with pure nitrogen, and subsequently, the reactor was flushed for a three day period exclusively with nitrogen gas. It was shown that the decreased $\mathrm{H}_{2}$ pressure led to an immediate degradation of VFA, whose final concentration reached $174 \mathrm{mg} / \mathrm{L}$ at the end of the aeration test. However, once the gas feedstock was restored to the initial composition (i.e. $23 \% \mathrm{CH}_{4}, 15 \% \mathrm{CO}_{2}$ and $62 \% \mathrm{H}_{2}$ ) the VFA content returned to the earlier levels (i.e. on average $759 \mathrm{mg} / \mathrm{L}$ ). The fast response of the TBF reactors' performance concordantly with the change of gas composition could be attributed to the formation of a well-structured microbial biofilm. It has been previously reported that the biofilm structure is a key parameter in anaerobic biofilm systems whose high process productivity is depended on interspecies $\mathrm{H}_{2}$ transfer (Annachhatre, 1996). In fact, at the end of the experiment a thin biofilm was created onto the surface of the packed material from which the microbial population was analysed.

Another interesting remark extracted from the VFA monitoring was related with the effect of the directional flow gases inside the TBF reactors. It was demonstrated that the injection of the influent gas mixture with the directional flow of the liquid in R2 greatly enhanced acetate production compared to the reactor that the gases were directed in countercurrent flow to the trickling media (R1). The countercurrent operation could 
influence the process presumably due to the densities of the different gases passing through the reactor. Indeed, $\mathrm{H}_{2}$ density is much lower than the ones of $\mathrm{CH}_{4}$ and $\mathrm{CO}_{2}$, and a downwards plug flow might involve higher $\mathrm{H}_{2}$ partial pressure in the liquid, compared to upflow operation, resulting in the promotion of homoacetogenesis.

Unlike the biomethanation trickle-bed research of Rachbauer et al., (2016), where the $\mathrm{pH}$ of the liquid media remained largely at neutral levels, in the present study, a continuous increment of $\mathrm{pH}$ was recorded even from the beginning of the experiment. The maximum $\mathrm{pH}$ value reached 8.63 ( $\mathrm{R} 2$ in Period $\mathrm{II}$ ), which is above the optimum threshold for methanogenesis (Kougias and Angelidaki, 2018), and therefore, a pH adjustment was mandatory as countermeasure for maintaining stable $\mathrm{pH}$ values. For this reason, $100 \mathrm{~mL}$ of liquid media were neutralised twice per week using $\mathrm{HCl} 1 \mathrm{M}$ and reintroduced in the nutrient glass vessel. The increment of the $\mathrm{pH}$ could be attributed to the $\mathrm{H}_{2}: \mathrm{CO}_{2}$ ratio fed to the reactors, which was slightly higher compared to the stoichiometric equation (i.e. $\mathrm{H}_{2}: \mathrm{CO}_{2}$ ratio was $4.13: 1$ ), resulting in an excess of $\mathrm{H}_{2}$ that concomitantly reduced the $\mathrm{CO}_{2}$ partial pressure. It is known that the $\mathrm{CO}_{2}$ produced during anaerobic digestion process reacts with the hydroxide ions $\left(\mathrm{OH}^{-}\right)$within the liquid, forming bicarbonate ions $\left(\mathrm{HCO}_{3}{ }^{-}\right)$that increase the buffering capacity of the medium (Schnurer and Jarvis, 2010). However, in the current case the injected $\mathrm{H}_{2}$ reacted with the $\mathrm{CO}_{2}$, reducing the $\mathrm{CO}_{2}$-partial pressure and provoking a loss of buffering capacity.

\subsection{Microbial community profiles in the liquid media and biofilm}

Illumina sequencing generated in total more than a million of raw reads with average length of $254 \mathrm{bp}$; results are summarized in Table 2. After quality filtering and 
pair merging, on average $63 \%$ of reads were taxonomically assigned to OTUs (Table 2). Rarefaction curves showed that the sequencing depth was adequate enough to cover the sample richness in the sample replicates. Microbial diversity was estimated and results showed 150 OTUs per replicate (on average). Principal coordinate analysis (PCoA) clearly indicated differences between the two samples, revealing a relative distance in their microbial beta diversity (Fig. 3). The replicates from the liquid media sample were all clustered together. One replicate of the biofilm sample showed lower similarity (Fig. 3) compared to the other two replicates (which clustered together) most probably due to technical issues (e.g. not homogenised sampling) and mainly influenced by the differences in only 3 abundant OTUs (Clostridia sp. 4, Thermoanaerobacteraceae sp. 10 and Tissierella sp. 11). However, for the rest of OTUs, the PCoA results were consistent in the three replicates, and thus, all of them were maintained for the analysis. As shown in Fig. 3, two completely different clusters were obtained regarding the samples from the liquid media or from the biofilm.

Considering the most abundant microbes $(>0.5 \%$ of relative abundance in at least one sample), 29 OTUs covered approximately $90 \%$ of the community in the samples. Among the selected OTUs, 8 were assigned at genus level and 6 at species level, while the rest of the microbes were assigned only at higher taxonomic levels, suggesting the presence in the microbiome of numerous underexplored or undescribed taxa.

Taxonomic assignment, relative abundance and abundance variation (fold change) of the most abundant OTUs in the samples are reported in Fig. 4. The fold change of OTUs significantly changing in relative abundance is shown in Fig. 5.

Bacterial population covered on average $90 \%$ and $70 \%$ of the whole microbial community in liquid media and biofilm samples, respectively, whilst archaea accounted 
on average for $10 \%$ and $30 \%$, respectively. Two different communities were obtained as in agreement with the previously discussed PCoA results (Fig. 3). In the liquid media samples, the most represented phyla were Firmicutes (40\%), Proteobacteria (22\%), Bacteroidetes (11\%) and Euryarchaeota (10\%), while the most abundant phyla in the biofilm samples were Firmicutes and Euryarchaeota (48\% and 30\%, respectively) with lower abundance of Proteobacteria (5\%) and Bacteroidetes (3\%). These phyla have been previously identified in the biofilm sample from the trickling biofilter working at mesophilic conditions in the study of Dupnock and Deshusses (2017). In their work, similar relative abundance of Euryarchaeota phylum (27\%) was found compared to the current study.

Among the most abundant OTUs, 3 of them were hydrogenotrophic methanogens assigned to Methanothermobacter sp. 1, Methanobacterium formicicum and Methanoculleus thermophilus (100, 97 and 100\% similarity, respectively). BLASTn search against NCBI database revealed $100 \%$ similarity of Methanothermobacter sp. 1 with two microbial species, such as Methanothermobacter thermautotrophicus and Methanothermobacter wolfeii, indicating that the most abundant methanogen populating the archaeal and total community was represented by a new species. Interestingly, these microorganisms were enriched in the biofilm compared to liquid media samples (Fig. 4). This fact could be explained as a consequence of their higher proximity with the carbon and hydrogen source in the biofilm and/or their possible syntrophic relationship with biofilm forming bacteria. Notably, Methanothermobacter sp. 1 was the most abundant microbe in the biofilm community (19\%) followed by M. formicicum (10\%) (Fig. 4). The abundance of these two hydrogenotrophic archaea was shown to be statistically higher in the biofilm compared to the liquid media (Fig. 5) and their ability 
to generate biofilms was reported in previous literature. M. thermautotrophicus was found to be one of the only two microorganisms populating the biofilm formed on top of the diffuser surface of an ex-situ biogas upgrading reactor (bubble column) at thermophilic conditions (Kougias et al. 2017). Moreover, Rademacher et al., (2012) identified the prevalence of this archaeon on a methanogenic biofilm in a thermophilic biogas system (two-phase leach-bed). In addition, the high abundance of Methanothermobacter sp. obtained in the present study in a TBF reactor is in agreement with previous studies which identified members this genus as dominant in thermophilic biogas upgrading systems operating using continuously stirred tank reactors (Treu et al., 2018; Kougias et al., 2017), bubble columns (Alfaro et al., 2018; Kougias et al., 2017) and up-flow reactors (Bassani et al., 2017). M. formicicum is known to be able to produce extracellular polysaccharides, which play various roles in structure and functions of biofilm communities (Veiga et al., 1997).

Although Thermoanaerobacteraceae sp. 10 was present in the liquid media (2\%), its relative abundance was higher in the biofilm (5\%) (Fig. 4). Members of this family (e.g. Moorella thermoacetica and Thermoanaerobacter kivui) are known homoacetogenic bacteria using $\mathrm{H}_{2}$ as electron donor to convert $\mathrm{CO}_{2}$ into acetate (Pierce et al., 2008; Weghoff and Müller, 2016). The best hit with 91\% similarity was a member of Moorella genus (Moorella humiferrea). Thus, Thermoanaerobacteraceae sp. could be a possible homoacetogen which is in accordance with the high VFA (772 mg/L, Fig. 2) and acetate $(656 \mathrm{mg} / \mathrm{L})$ contents observed in R2 at the sampling moment for the microbial analysis. Tepidanaerobacter syntrophicus (98\% similarity) was found in all microbial communities (Fig. 4). Previous studies (Sekiguchi et al., 2006) reported the syntrophic association of this microorganism with the hydrogenotrophic methanogen $M$. 
thermoautotrophicus and its ability to utilise ethanol, glycerol and lactate syntrophically for growth. Thus, the statistical higher relative abundance of $T$. syntrophicus in the biofilm samples compared to liquid media (Fig. 5) was in agreement with the significant higher abundance of its partner Methanothermobacter sp. in the biofilm (Fig. 4, Fig. 5). Bacillus infernus (100\% similarity) was found to be enriched in the biofilm (Fig. 4) with statistical relative abundance differences (Fig. 5) compared to liquid media. This $B$. infernus richness in the biofilm agrees with the findings reported by Kougias et al. (2017) about higher relative abundance of this microbe in the biofilm compared to the liquid phase of a thermophilic bubble column reactor used for biogas upgrading. $B$. infernus, a metal-reducing bacterium, is known to create biofilms in order to perform extracellular electron transfer (Badalamenti et al., 2013). In anaerobic digestion systems, the interspecies electron transfer is a fundamental feature between bacteria and archaea in order to maintain the redox reactions in sufficiently exergonic levels (Kougias et al., 2016).

Clostridia sp. 2 was the second (15\%) and the third (10\%) most abundant OTU of the community in liquid media and biofilm samples, respectively. This species was assigned to the recently discovered order MBA08, belonging to Clostridia class. BLAST results of this OTU's consensus sequence indicated a high similarity to Hydrogenispora ethanolica (90\%) and confirmed the relevance of this uncharacterized OTU previously found in other works dealing with biogas upgrading (Bassani et al., 2017; Corbellini et al., 2018; Kougias et al., 2017; Treu et al., 2018b). In addition, Kougias et al. (2017) indicated the existence of a potential syntrophic interaction between the hydrogenotrophic methanogen M. thermautotrophicus and Clostridia sp. 2 (H. ethanolica) because of their concurrent remarkable high abundance. Interestingly, 
Clostridia sp. 2 was present in high abundance in the biofilm and the liquid media, thus suggesting its possible versatile metabolism.

The relative abundance differences of Pseudomonas sp. 3 and Bacteroidales sp. 6 were statistically higher in the liquid media than in the biofilm as shown in Fig. 5. Both microorganisms presented high relative abundance values (16\% and $10 \%$, respectively) in the liquid media samples compared to biofilm samples and they were two of the highest abundant microbes in the liquid media (Fig. 4). The richness of Pseudomonas sp. in the liquid media compared to the biofilm was in agreement with the findings of Kougias et al. (2017) obtained in the samples from biofilm and liquid phase of their exsitu biogas upgrading bubble column reactor experiment at thermophilic conditions. By performing a BLASTn search against the NCBI database, this OTU was similar to Pseudomonas flexibilis (95\%). Literature reported not only a marked stimulated growth of Pseudomonas flexibilis utilising lactate as a carbon and energy source but also stimulated growth by means of acetate and $\alpha$-ketoglutarate (Herspell, 1977). Thus, as an acetate utiliser, its relative abundance was higher in the liquid media, which agrees with the high concentration of acetate found in $\mathrm{R} 2(656 \mathrm{mg} / \mathrm{L})$ in the liquid.

Bacteroidales sp.6 was the third most abundant OTU in liquid media samples (10\%) and an "unclassified species" belonging to the order Bacteroidales. The taxonomic assignment could not be improved neither by BLASTn search against the NCBI database, nor by aligning the sequence against other public databases, such as RDP Classifier or SILVA ribosomal RNA gene database. The best hit with $81 \%$ similarity was with an obligatory anaerobic asaccharolytic member of Porphyromonas genus (Porphyromonas circumdentaria). This uncharacterized OTU was previously found in other works dealing with biogas upgrading (Kougias et al., 2017). Similarly to 
Pseudomonas sp. 3, Bacteroidales sp. 6 could be an acetate utiliser regarding its high abundance in the liquid media. This fact was also supported by the high acetate concentration in R2 on day 94 mentioned above.

\subsection{Practical considerations derived from the current study}

The proposed biomethanation concept is becoming an attractive technology considering: a) the fact that $\mathrm{H}_{2}$ used for the $\mathrm{CO}_{2}$ hydrogenation can be generated from renewable energy sources via water electrolysis (Götz et al., 2015), and b) the high costs associated with $\mathrm{H}_{2}$ storage (Gahleitner, 2013). A question that needs to be addressed is related with the robustness of the process; commonly, renewable energy is a temporarily surplus, and thus, it is mandatory to elucidate the biomethanation efficiency during intermittent provision of $\mathrm{H}_{2}$. Therefore, a preliminary test was conducted in which the gas feed was interrupted for 22 hours. After restarting the influx, a decline in output gas quality was observed (i.e. $91 \%$ of $\mathrm{CH}_{4}$ content). The quality of the output gas was increased to $94 \%$ after approximately 3.5 hours, while it fully recovered to $98 \%$ after 20h. This result is in accordance with other studies, which affirm that dormant cultures can be quickly reactivated in large-scale AD systems, and that methanogens can be fed intermittently (Lettinga, 1995; Martin et al., 2013). Additionally, this result agrees with the achievement potential recovery obtained in previous biogas upgrading TBF reactors after three days of $\mathrm{H}_{2}$ suspension at mesophilic conditions (Burkhardt et al., 2015) and after one day of $\mathrm{H}_{2}$ lack at thermophilic conditions (Strübing et al., 2017). Nevertheless, further research related to the microbial tolerance towards periodical $\mathrm{H}_{2}$ provision should be undertaken in order to draw conclusions on the dynamic operation of the presented system. 
It is previously documented that the TBF reactors can produce high volumetric concentrations of $\mathrm{CH}_{4}$ (Rittmann, 2015), and thus, are attractive configurations for the overall biomethanation process. The produced gas in all the experimental periods was of sufficient quality to be introduced in natural gas infrastructures (Muñoz et al., 2015). Nevertheless, the tested TBF reactors could be considerably improved and optimized by enabling a faster process (i.e. lowering the gas retention time), or by reducing the specific reactor volume, which would lead to a decrease of the CAPEX. For instance, optimisation of the $\mathrm{H}_{2}: \mathrm{CO}_{2}$ ratio, together with adoption of more suitable packed-bed elements would involve inexpensive performance improvements. Additionally, the liquid recirculation rate is considered as another key point for enhancing the efficiency of the system. In other studies (Burkhardt et al., 2015), reduction of the liquid recirculation rate was found to increase the performance of the TBF.

Previous works on biological biogas upgrading reported that the low gas liquid mass transfer is a bottleneck for achieving high bioconversion rates (Angelidaki et al., 2018; Szuhaj et al., 2016). However, in the TBF reactors the gas-liquid boundary surface formed over the packed bed is maximised allowing a better and more homogenised dispersion of the injected gasses. Moreover, given that biofilms rapidly consume accessible nutrients, high concentration gradients of the gases (in the current case $\mathrm{H}_{2}$ and $\mathrm{CO}_{2}$ ) are formed throughout the 3-phase system, triggering their favourable transport into the biofilm in accordance to Henry's law (Pauss et al., 1990). $\mathrm{H}_{2}$ masstransfer is therefore improved passively, without need of liquid stirring, diffusion devices or gas recirculation. Additionally, pressurisation of the reactors has been proven to reduce the $\mathrm{H}_{2}$ mass-transfer limitations (Martin et al., 2013). Nevertheless, an advantage of the presented concept is that the biomethanation occurs at atmospheric 
pressure, resulting in low technical requirements and economical costs.

Unlike catalytic methanation systems (Benjaminsson et al., 2013), it has been proven that chemical contaminants, such as $\mathrm{H}_{2} \mathrm{~S}$ or $\mathrm{NH}_{3}$, do not disturb the biological methanation technologies, neither in trickle-bed reactors (Burkhardt et al., 2015), nor in liquid-phase systems (Martin et al., 2013). This aspect offers great a potential to the exploitation of biological methods for upgrading the quality of biogas. Finally, considering all the outcomes from the present work, it can be extracted that the combination of biological methanation technology with the utilisation of TBF reactor systems seems very convenient for application in the Power-to-Gas concept.

\section{Conclusions}

The present work demonstrates the suitability of thermophilic trickling biofilters for methanation of $\mathrm{H}_{2}$ and the $\mathrm{CO}_{2}$ fraction of biogas. Stable and robust continuous operation was achieved through single-pass plug flow, without need for gas mixing or recirculation. The investigated system upgraded biogas efficiently reaching a $\mathrm{CH}_{4}$ concentration above $97 \%$, and $\mathrm{CH}_{4}$ productivity of more than $1.7 \mathrm{~L}_{\mathrm{CH}} /\left(\mathrm{L}_{\mathrm{R}} \cdot \mathrm{d}\right)$, for a $\mathrm{H}_{2}$ loading rate $Q_{\mathrm{H}_{2}, I N}$ of $7.2 \mathrm{LH}_{2} /\left(\mathrm{L}_{\mathrm{R}} \cdot \mathrm{d}\right)$. Regarding the microbial community structure, it was shown that the most abundant methanogen populating the microbial community (Methanothermobacter sp.) was represented by a new species.

\section{Acknowledgement}

We thank Hector Díaz and Hector Garcia for the technical support. This work was supported by the Innovation Fund Denmark under the project "SYMBIO - Integration of biomass and wind power for biogas enhancement and upgrading via hydrogen 
assisted anaerobic digestion", contract 12-132654. Illumina sequencing was performed at the Ramaciotti Centre for Genomics (Sydney, Australia).

\section{References}

Ahern, E.P., Deane, P., Persson, T., Ó Gallachóir, B., Murphy, J.D., 2015. A perspective on the potential role of renewable gas in a smart energy island system. Renew. Energy 78, 648-656.

Alfaro, N., Fdz-Polanco, M., Fdz-Polanco, F., Díaz, I., 2018. Evaluation of process performance, energy consumption and microbiota characterization in a ceramic membrane bioreactor for ex-situ biomethanation of $\mathrm{H}_{2}$ and $\mathrm{CO}_{2}$. Bioresour. Technol. 258, 142-150.

Alitalo, A., Niskanen, M., Aura, E., 2015. Biocatalytic methanation of hydrogen and carbon dioxide in a fixed bed bioreactor. Bioresour. Technol. 196, 600-605.

Angelidaki, I., Treu, L., Tsapekos, P., Luo, G., Campanaro, S., Wenzel, H., Kougias, P.G., 2018. Biogas upgrading and utilization: Current status and perspectives. Biotechnol. Adv. 36, 452-466.

Annachhatre, a. P., 1996. Anaerobic treatment of industrial wastewaters. Resour. Conserv. Recycl. 16, 161-166.

APHA, 2005. Standard Methods for the Examination of Water and Wastewater. American Public Health Association, Washington, DC, USA.

Badalamenti, J.P., Krajmalnik-brown, R., Torres, C.I., 2013. Generation of High Current Densities by Pure Cultures of Anode- Respiring Geoalkalibacter spp . under Alkaline and Saline Conditions. MBio 4, 1-8.

Bassani, I., Kougias, P.G., Angelidaki, I., 2016. In-situ biogas upgrading in thermophilic granular UASB reactor: key factors affecting the hydrogen mass transfer rate. Bioresour. Technol. 221, 485-491.

Bassani, I., Kougias, P.G., Treu, L., Porté, H., Campanaro, S., Angelidaki, I., 2017. Optimization of hydrogen dispersion in thermophilic up-flow reactors for ex situ biogas upgrading. Bioresour. Technol. 234, 310-319.

Benjaminsson, G., Benjaminsson, J., Rudberg, R.B., 2013. Power to Gas - a Technical Review. SGC - Sven. Gastek. Cent. AB, Malmö, Sweden, Rep. 256. 
Bhandari, R., Trudewind, C.A., Zapp, P., 2014. Life cycle assessment of hydrogen production via electrolysis - a review. J. Clean. Prod. 85, 151-163.

Burkhardt, M., Koschack, T., Busch, G., 2015. Biocatalytic methanation of hydrogen and carbon dioxide in an anaerobic three-phase system. Bioresour. Technol. 178, 330-333.

Collet, P., Flottes, E., Favre, A., Raynal, L., Pierre, H., Capela, S., Peregrina, C., 2017. Techno-economic and Life Cycle Assessment of methane production via biogas upgrading and power to gas technology. Appl. Energy 192, 282-295.

Corbellini, V., Kougias, P.G., Treu, L., Bassani, I., Malpei, F., Angelidaki, I., 2018. Hybrid biogas upgrading in a two-stage thermophilic reactor. Energy Convers. Manag. 168, 1-10.

Díaz, I., Pérez, C., Alfaro, N., Fdz-Polanco, F., 2015. A feasibility study on the bioconversion of $\mathrm{CO}_{2}$ and $\mathrm{H}_{2}$ to biomethane by gas sparging through polymeric membranes. Bioresour. Technol. 185, 246-253.

Dupnock, T.L., Deshusses, M.A., 2017. High-Performance Biogas Upgrading Using a Biotrickling Filter and Hydrogenotrophic Methanogens. Appl. Biochem. Biotechnol. 183, 488-502.

Fukuzaki, S., Nishio, N., Shobayashi, M., Nagai, S., 1990. Inhibition of the fermentation of propionate to methane by hydrogen, acetate, and propionate. Appl. Environ. Microbiol. 56, 719-723.

Gahleitner, G., 2013. Hydrogen from renewable electricity: An international review of power-to-gas pilot plants for stationary applications. Int. J. Hydrogen Energy 38, 2039-2061.

Garrett, T.R., Bhakoo, M., Zhang, Z., 2008. Bacterial adhesion and biofilms on surfaces. Prog. Nat. Sci. 18, 1049-1056.

Götz, M., Lefebvre, J., Mörs, F., McDaniel Koch, A., Graf, F., Bajohr, S., Reimert, R., Kolb, T., 2015. Renewable Power-to-Gas: A technological and economic review. Renew. Energy 85, 1371-1390.

Guinot, B., Montignac, F., Champel, B., Vannucci, D., 2015. Profitability of an electrolysis based hydrogen production plant providing grid balancing services. Int. J. Hydrogen Energy 40, 8778-8787.

Herspell, R.B., 1977. Serpens flexibilis gen. nov., sp. nov., an unusually flexible, 
lactate-oxidizing bacterium. Int. J. Syst. Evol. Microbiol. 27, 371-381.

Hori, K., Matsumoto, S., 2010. Bacterial adhesion: From mechanism to control. Biochem. Eng. J. 48, 424-434.

Ju, D.-H., Shin, J.-H., Lee, H.-K., Kong, S.-H., Kim, J.-I., Sang, B.-I., 2008. Effects of $\mathrm{pH}$ conditions on the biological conversion of carbon dioxide to methane in a hollow-fiber membrane biofilm reactor (Hf-MBfR). Desalination 234, 409-415.

Kougias, P.G., Angelidaki, I., 2018. Biogas and its opportunities-A review. Front. Environ. Sci. Eng. 12.

Kougias, P.G., Boe, K., Einarsdottir, E.S., Angelidaki, I., 2015. Counteracting foaming caused by lipids or proteins in biogas reactors using rapeseed oil or oleic acid as antifoaming agents. Water Res. 79, 119-127.

Kougias, P.G., Treu, L., Benavente, D.P., Boe, K., Campanaro, S., Angelidaki, I., 2017. Ex-situ biogas upgrading and enhancement in different reactor systems. Bioresour. Technol. 225, 429-437.

Kougias, P.G., Treu, L., Campanaro, S., Zhu, X., Angelidaki, I., 2016. Dynamic functional characterization and phylogenetic changes due to Long Chain Fatty Acids pulses in biogas reactors. Sci. Rep. 6, 28810.

Langer, S., Schropp, D., Bengelsdorf, F.R., Othman, M., Kazda, M., 2014. Dynamics of biofilm formation during anaerobic digestion of organic waste. Anaerobe 29, 4451.

Lettinga, G., 1995. Anaerobic digestion and wastewater treatment systems. Antonie Van Leeuwenhoek, anaerobic 67, 3-28.

Martin, M.R., Fornero, J.J., Stark, R., Mets, L., Angenent, L.T., 2013. A Single-Culture Bioprocess of Methanothermobacter thermautotrophicus to Upgrade Digester Biogas by $\mathrm{CO}_{2}$-to- $\mathrm{CH}_{4}$ Conversion with $\mathrm{H}_{2}$. Archaea 2013, 1-11. doi:10.1155/2013/157529

Muñoz, R., Meier, L., Diaz, I., Jeison, D., 2015. A review on the state-of-the-art of physical/chemical and biological technologies for biogas upgrading. Rev. Environ. Sci. Bio/Technology 14, 727-759.

Parks, D.H., Beiko, R.G., 2010. Identifying biologically relevant differences between metagenomic communities. Bioinformatics 26, 715-721.

Pauss, A., Andre, G., Perrier, M., Guiot, S.R., 1990. Liquid-to-gas mass transfer in 
anaerobic processes: inevitable transfer limitations of methane and hydrogen in the biomethanation process. Appl. Environ. Microbiol. 56, 1636-1644.

Persson, T., Murphy, J., Jannasch, A.-K., Liebetrau, J., Toya, J., Ahern, E., Trommler, M., 2015. A Perspective on the Potential Role of Biogas in Smart Energy Grids, 2014. IEA Bioenergy, Dublin 9.

Pierce, E., Xie, G., Barabote, R.D., Saunders, E., Han, C.S., Detter, J.C., Richardson, P., Brettin, T.S., Das, A., Ljungdahl, L.G., Ragsdale, S.W., 2008. The complete genome sequence of Moorella thermoacetica (f. Clostridium thermoaceticum). Environ. Microbiol. 10, 2550-2573. doi:10.1111/j.1462-2920.2008.01679.x

Rachbauer, L., Beyer, R., Bochmann, G., Fuchs, W., 2017. Characteristics of adapted hydrogenotrophic community during biomethanation. Sci. Total Environ. 595, 912-919.

Rachbauer, L., Voitl, G., Bochmann, G., Fuchs, W., 2016. Biological biogas upgrading capacity of a hydrogenotrophic community in a trickle-bed reactor. Appl. Energy $180,483-490$.

Rademacher, A., Zakrzewski, M., Schlüter, A., Schönberg, M., Szczepanowski, R., Goesmann, A., Pühler, A., Klocke, M., 2012. Characterization of microbial biofilms in a thermophilic biogas system by high-throughput metagenome sequencing. FEMS Microbiol. Ecol. 79, 785-799.

Rittmann, S.K.-M.R., 2015. A Critical Assessment of Microbiological Biogas to Biomethane Upgrading Systems, in: Guebitz, G.M., Bauer, A., Bochmann, G., Gronauer, A., Weiss, S. (Eds.), Biogas Science and Technology. Springer International Publishing, Cham, pp. 117-135.

Saeed, A.I., Sharov, V., White, J., Li, J., Liang, W., Bhagabati, N., Braisted, J., Klapa, M., Currier, T., Thiagarajan, M., Sturn, A., Snuffin, M., Rezantsev, A., Popov, D., Ryltsov, A., Kostukovich, E., Borisovsky, I., Liu, Z., Vinsavich, A., Trush, V., Quackenbush, J., 2003. TM4: a free, open-source system for microarray data management and analysis. Biotechniques 34, 374-378.

Schnurer, A., Jarvis, A., 2010. Microbiological handbook for biogas plants. Avfall Sverige and Swedish Gas Centre (SGC).

Sekiguchi, Y., Imachi, H., Susilorukmi, A., Muramatsu, M., Ohashi, A., Harada, H., Hanada, S., Kamagata, Y., 2006. Tepidanaerobacter syntrophicus gen. nov., sp. 
nov., an anaerobic, moderately thermophilic, syntrophic alcohol- and lactatedegrading bacterium isolated from thermophilic digested sludges. Int. J. Syst. Evol. Microbiol. 56, 1621-1629.

Strübing, D., Huber, B., Lebuhn, M., Drewes, J.E., Koch, K., 2017. High performance biological methanation in a thermophilic anaerobic trickle bed reactor. Bioresour. Technol. 245, 1176-1183.

Sun, Q., Li, H., Yan, J., Liu, L., Yu, Z., Yu, X., 2015. Selection of appropriate biogas upgrading technology-a review of biogas cleaning, upgrading and utilisation. Renew. Sustain. Energy Rev. 51, 521-532.

Szuhaj, M., Ács, N., Tengölics, R., Bodor, A., Rákhely, G., Kovács, K.L., Bagi, Z., 2016. Conversion of $\mathrm{H}_{2}$ and $\mathrm{CO}_{2}$ to $\mathrm{CH}_{4}$ and acetate in fed-batch biogas reactors by mixed biogas community: a novel route for the power-to-gas concept. Biotechnol. Biofuels 9, 102.

Treu, L., Campanaro, S., Kougias, P.G., Sartori, C., Bassani, I., Angelidaki, I., 2018a. Hydrogen-fueled microbial pathways in biogas upgrading systems revealed by genome-centric metagenomics. Front. Microbiol. 9.

Treu, L., Kougias, P.G., de Diego-Díaz, B., Campanaro, S., Bassani, I., FernándezRodríguez, J., Angelidaki, I., 2018b. Two-year microbial adaptation during hydrogen-mediated biogas upgrading process in a serial reactor configuration. Bioresour. Technol. 264.

Veiga, M.C., Jain, M.K., Wu, W.M., Hollingsworth, R.I., Zeikus, J.G., 1997. Composition and role of extracellular polymers in methanogenic granules. Appl. Environ. Microbiol. 63, 403-407.

Wang, W., Xie, L., Luo, G., Zhou, Q., Angelidaki, I., 2013. Performance and microbial community analysis of the anaerobic reactor with coke oven gas biomethanation and in situ biogas upgrading. Bioresour. Technol. 146, 234-239. doi:10.1016/j.biortech.2013.07.049

Weghoff, M.C., Müller, V., 2016. CO metabolism in the thermophilic acetogen Thermoanaerobacter kivui. Appl. Environ. Microbiol. 82, 2312-2319.

Yun, Y.M., Sung, S., Kang, S., Kim, M.S., Kim, D.H., 2017. Enrichment of hydrogenotrophic methanogens by means of gas recycle and its application in biogas upgrading. Energy 135, 294-302. 

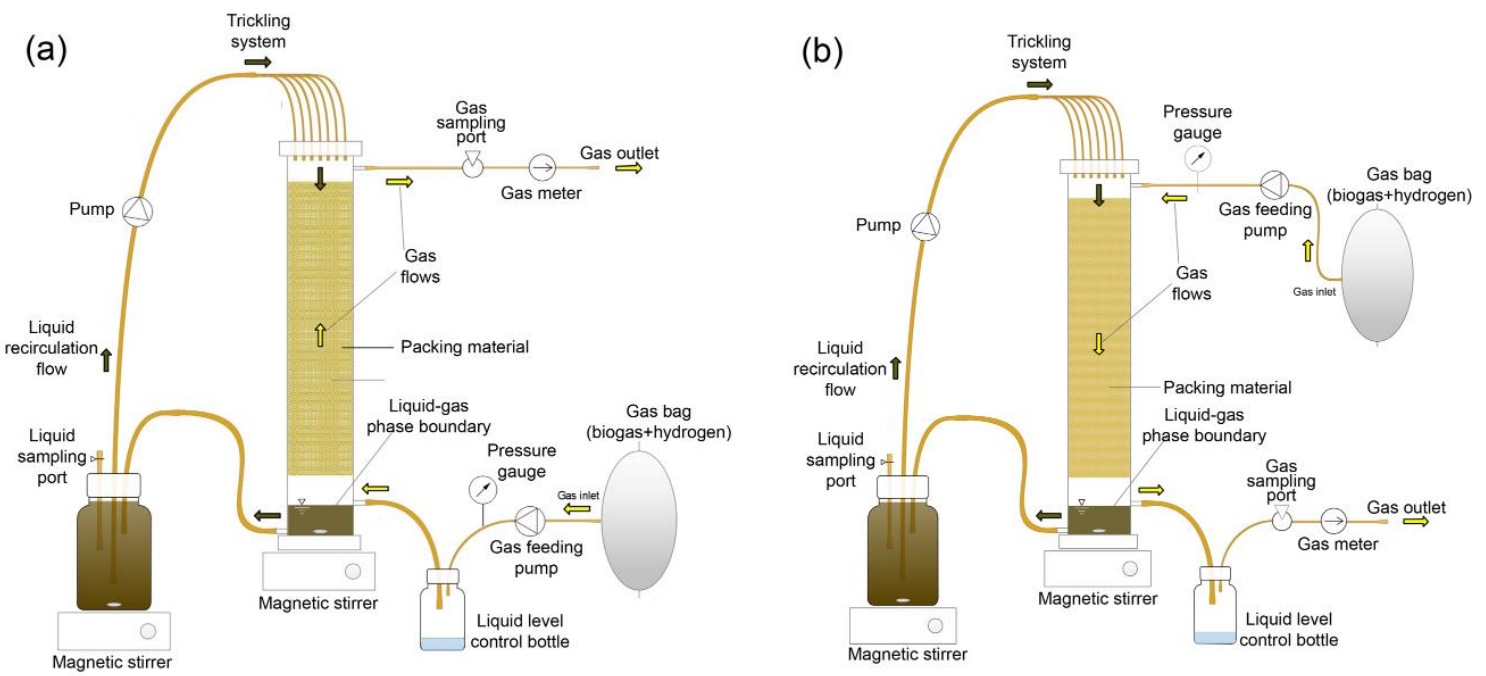

Fig. 1. Schematic representation of the trickling biofilter reactors. 

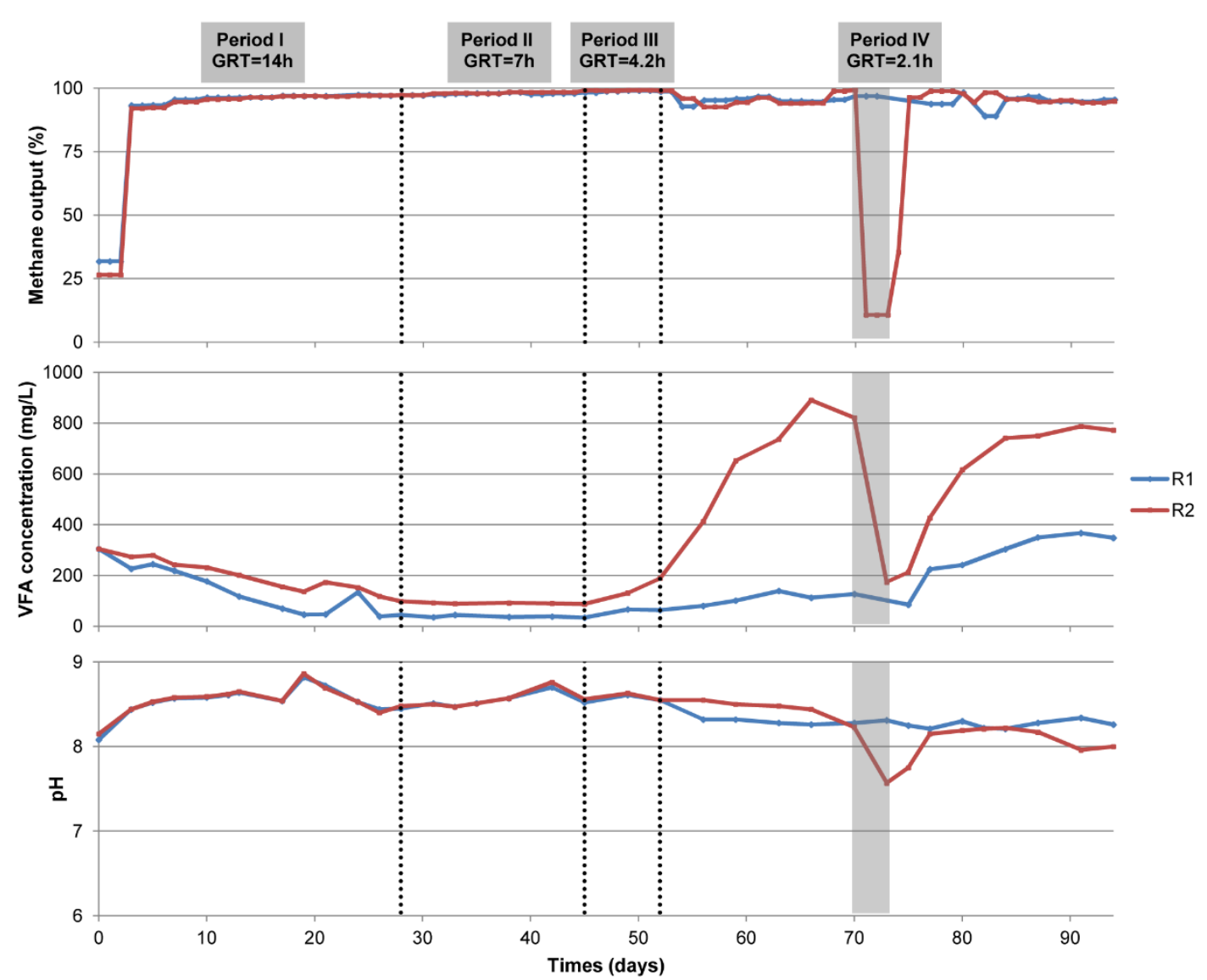

Fig. 2. Evolution of methane concentration in the effluent gas, VFA concentration

676 and $\mathrm{pH}$ values in the reactors throughout the experiment. The shaded area represents the

677 period in which the gas mixture of R2 was temporarily changed with pure nitrogen. 


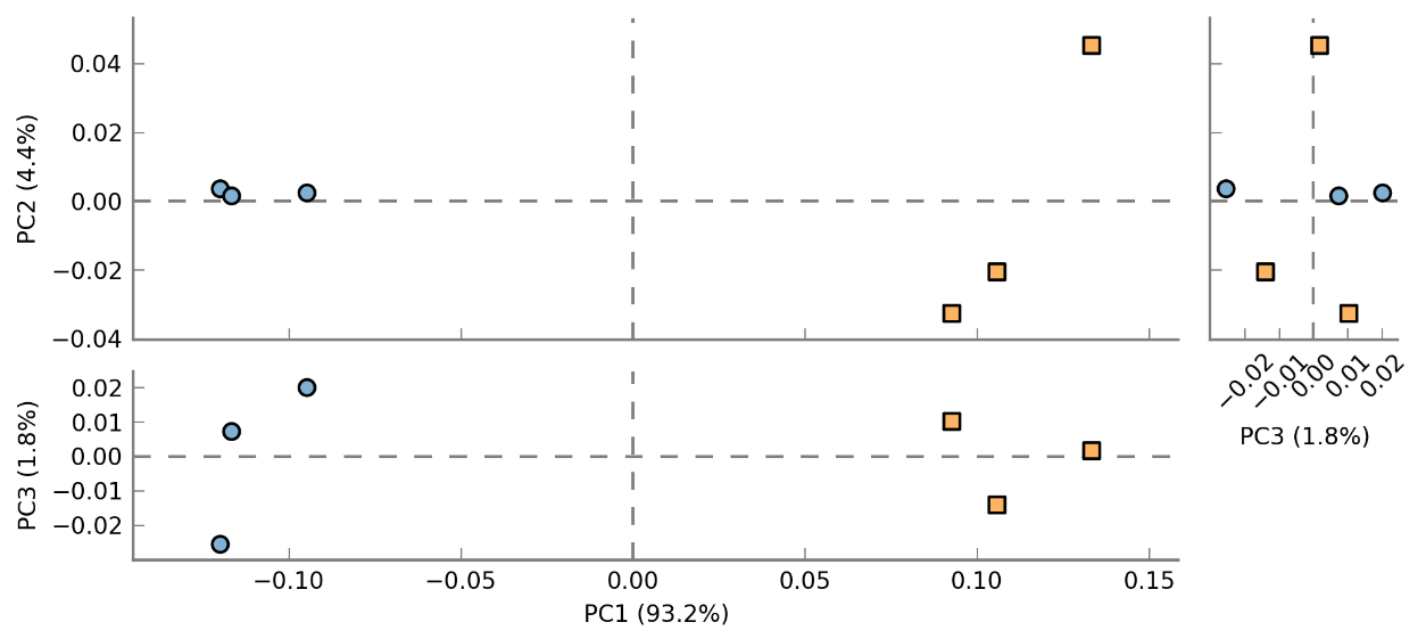

679

Fig.3. Principal coordinate analysis plot representing variations of the most

681 abundant OTUs based on least squares method. Orange colour represents the biofilm

682 samples while blue colour designates the liquid media samples. 
(a)

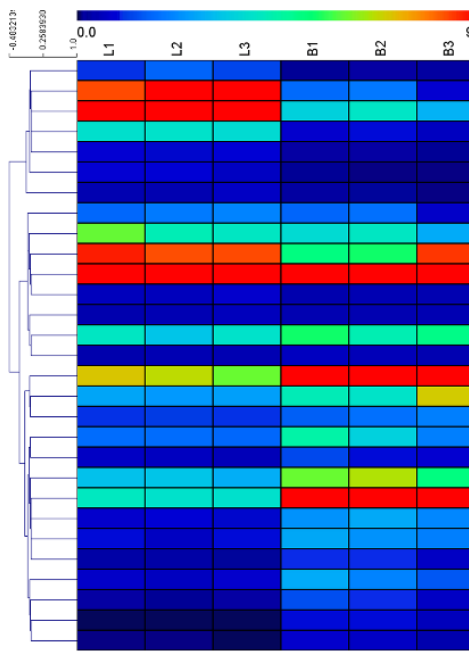

Thermoanaerobacteraceae sp. 19 Bacteroidales sp. 6 Pseudomonas sp. 12 Comamonadaceae sp. 23 Amphibacillus sp. 26 Firmicutes sp. 28 Bacteroidia sp. 13 Anaerobaculum sp. 9 Clostridia sp. 2

Firmicutes sp. 22

Alkalispirillum sp. 24

Thermoanaerobacterales sp. 8

[Bacillus] thermocloacae sp. 25

Methanothermobacter sp.

Thermoanaerobacteraceae sp. 10 Clostridia sp. 16

Thermoanaerobacteraceae sp. 18

Bacillus infernus 7 .

Methanobacterium formicicum 5

Haloplasmatales sp. 14
Paenibacillaceae sp. 15

Lutispora sp. 20

Tepidanaerobacter sp. 17

Tepidanaerobacter syntrophicus 2

Methanoculleus thermophilus 27 (b)
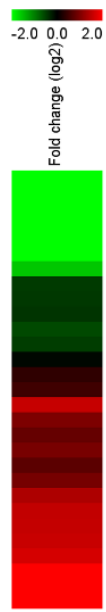

Thermoanaerobacteraceae sp. 19 Pseudomonas sp. 3 seudomonas sp. 12 . 23
Comamonadaceae sp. 23 Firmicutes sp. 28.26 Bacteroidia sp. 13
Anaerobaculum sp. 9 Anastridas sp. 4 .
Clostridia sp. 2 . Firmicutes sp. 22
Alkalispirilum sp. 24 Thermoanaerobacterales sp. 8 Methanothermobacter $\mathrm{sp} .125$ Clostridia sp. 16
Tissierella sp. 11 Thermoanaerobacteraceae sp. 18
Bacillus infernus 7 Methanobacterium formicicum 5 Maloplasmatales sp. 14
Paenibaciliaceae sp. 15 Lutisporas $\mathrm{p}_{2} 20 \mathrm{ps} .1 \mathrm{~s}$ Tepidanaerobacter sp. 17
Tepidanaerobacter syntrophicus 21 Tepidanaerobacter syntrophicus 2
Methanoculleus thermophilus 27

Fig. 4. (a) Heat maps of relative abundance (\%) and (b) fold change $(\log 2)$ of the most abundant microorganisms populating R2 in the liquid media (L) and in the biofilm (B). Correspondence between colours and relative abundance or fold change is reported

689 in the scale at the top of each panel. Fold change is represented in red and green for 690 increased and decreased OTUs, respectively. 


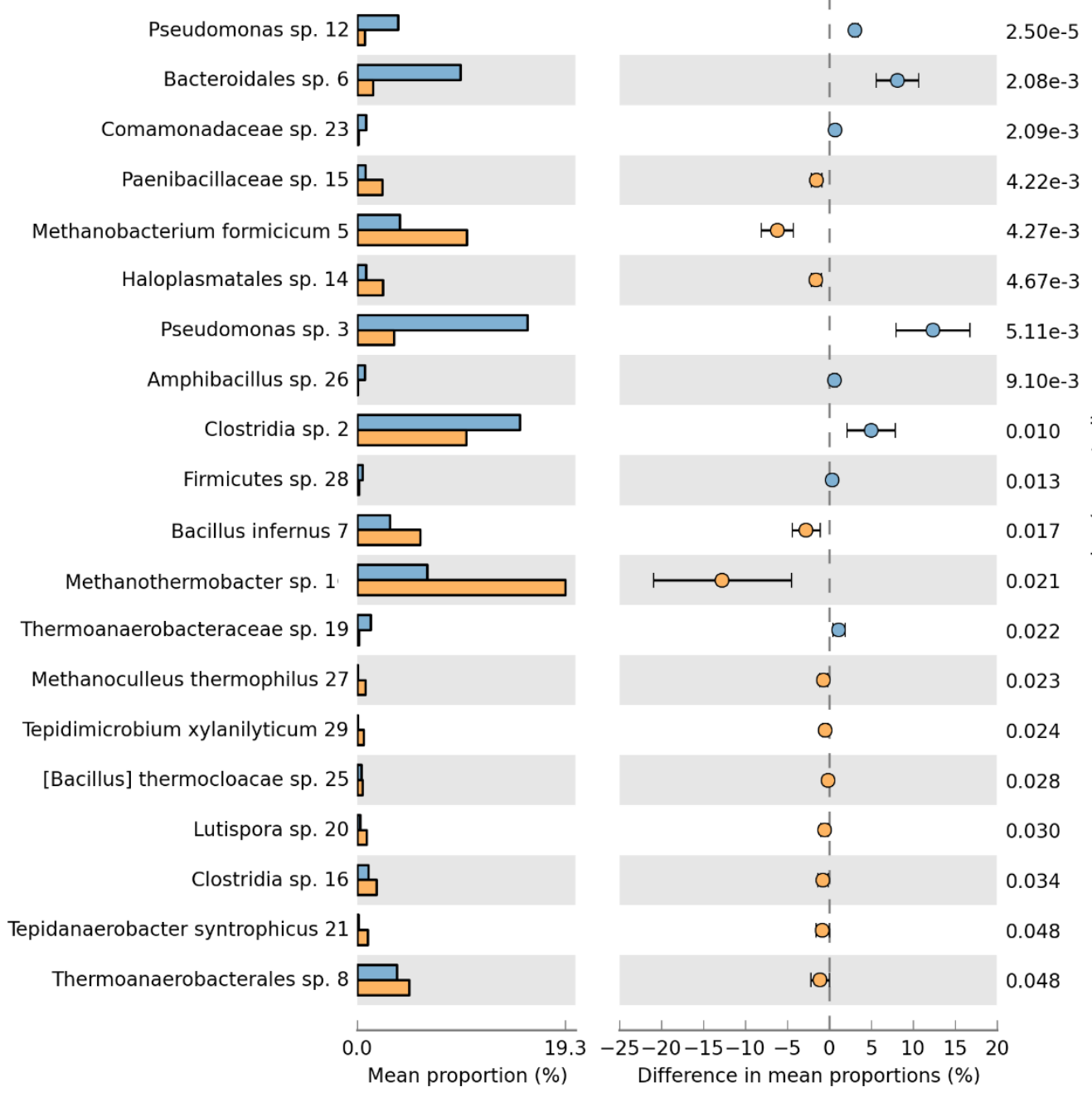

Fig. 5. Statistical comparison between sample from the liquid media (blue colour)

695 and sample from the biofilm (orange colour). The left part of the panel represents the

696 relative abundance $(>0.5 \%)$ while the right part shows the fold change of OTUs

697 significantly changing in abundance (differences in mean proportions) as well as the confidence interval associated and the p-value. 


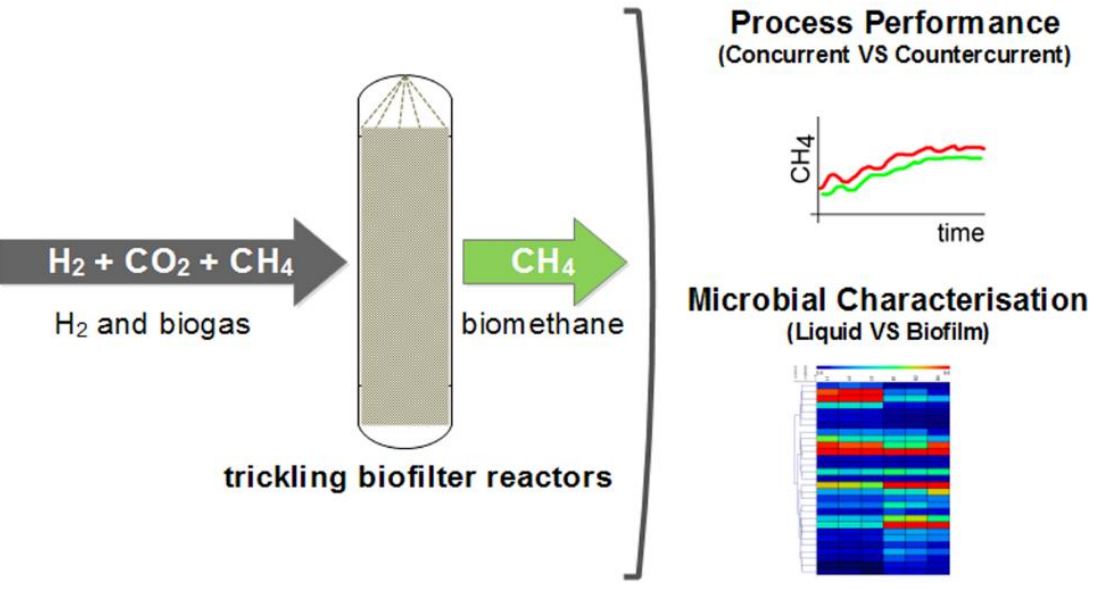


Table 1. Overview of reactors' performance during their steady state operation at each experimental period.

\begin{tabular}{|c|c|c|c|c|c|c|c|c|}
\hline & \multicolumn{2}{|c|}{$\begin{array}{c}\text { Period I } \\
\text { Days 0-28 }\end{array}$} & \multicolumn{2}{|c|}{$\begin{array}{c}\text { Period II } \\
\text { Days 29-45 }\end{array}$} & \multicolumn{2}{|c|}{$\begin{array}{c}\text { Period III } \\
\text { Days 46-52 }\end{array}$} & \multicolumn{2}{|c|}{$\begin{array}{c}\text { Period IV } \\
\text { Days 53-94 }\end{array}$} \\
\hline & R1 & $\mathbf{R 2}$ & R1 & $\mathbf{R 2}$ & $\mathbf{R 1}$ & $\mathbf{R 2}$ & $\mathbf{R 1}$ & $\mathbf{R 2}$ \\
\hline Gas Retention time, $\mathrm{h}$ & 14 & 14 & 7 & 7 & 4.2 & 4.2 & 2.1 & 2.1 \\
\hline $\begin{array}{l}\mathrm{H}_{2} \text { loading rate, } \\
\mathrm{L}_{\mathrm{H} 2} /\left(\mathrm{L}_{\mathrm{R}} \cdot \mathrm{d}\right)\end{array}$ & 1.1 & 1.1 & 2.2 & 2.2 & 3.6 & 3.6 & 7.2 & 7.2 \\
\hline $\mathrm{CH}_{4}$ content, $\%$ & $97.3 \pm 0.6$ & $97.0 \pm 0.1$ & $98.0 \pm 0.4$ & $98.1 \pm 0.2$ & $98.7 \pm 0.3$ & $99.1 \pm 0.1$ & $95.1 \pm 0.5$ & $94.9 \pm 0.6$ \\
\hline $\begin{array}{l}\mathrm{CH}_{4} \text { production rate, } \\
\mathrm{L}_{\mathrm{CH}} 4 /\left(\mathrm{L}_{\mathrm{R}} \cdot \mathrm{d}\right)\end{array}$ & $0.26 \pm 0.03$ & $0.25 \pm 0.01$ & $0.50 \pm 0.02$ & $0.50 \pm 0.00$ & $0.89 \pm 0.01$ & $0.88 \pm 0.01$ & $1.74 \pm 0.01$ & $1.71 \pm 0.03$ \\
\hline $\begin{array}{l}\mathrm{H}_{2} \text { utilisation } \\
\text { efficiency, } \%\end{array}$ & $95.3 \pm 2.1$ & $97.5 \pm 0.6$ & $91.2 \pm 4.6$ & $96.8 \pm 0.7$ & $99.9 \pm 0.1$ & $99.8 \pm 0.1$ & $97.2 \pm 0.6$ & $96.8 \pm 0.4$ \\
\hline $\begin{array}{l}\mathrm{CO}_{2} \text { utilisation } \\
\text { efficiency, } \%\end{array}$ & $93.2 \pm 1.5$ & $92.5 \pm 0.4$ & $94.9 \pm 0.9$ & $96.2 \pm 0.6$ & $97.5 \pm 0.6$ & $98.2 \pm 0.5$ & $98.9 \pm 0.0$ & $99.9 \pm 0.1$ \\
\hline 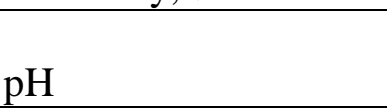 & $8.56 \pm 0.18$ & $8.58 \pm 0.17$ & $8.60 \pm 0.09$ & $8.63 \pm 0.11$ & $8.58 \pm 0.04$ & $8.59 \pm 0.06$ & $8.29 \pm 0.03$ & $8.12 \pm 0.14$ \\
\hline VFA, mg/L & $49 \pm 14$ & $132 \pm 24$ & $36 \pm 2$ & $89 \pm 2$ & $65 \pm 2$ & $159 \pm 41$ & $342 \pm 27$ & $759 \pm 25$ \\
\hline Acetate, $\mathrm{mg} / \mathrm{L}$ & $41 \pm 11$ & $113 \pm 23$ & $31 \pm 2$ & $70 \pm 3$ & $50 \pm 5$ & $116 \pm 31$ & $298 \pm 26$ & $643 \pm 7$ \\
\hline
\end{tabular}


Table 2. Summary of the sequencing data and results

\begin{tabular}{|c|c|c|c|c|}
\hline Sample ID & Sample Description & Raw Reads & Assigned Reads & SRA accession IDs \\
\hline L1 & Liquid sample from R2 & 198594 & 58195 & SAMN09655204 \\
\hline L2 & Liquid sample from R2 & 236364 & 66295 & SAMN09655204 \\
\hline L3 & Liquid sample from R2 & 226410 & 64031 & SAMN09655204 \\
\hline B1 & Biofilm from R2 & 281440 & 78131 & SAMN09655205 \\
\hline B2 & Biofilm from R2 & 247640 & 68069 & SAMN09655205 \\
\hline B3 & Biofilm from R2 & 105686 & 25345 & SAMN09655205 \\
\hline
\end{tabular}

